\title{
Hypertonic glucose inhibits growth and attenuates virulence factors of multidrug- resistant Pseudomonas aeruginosa
}

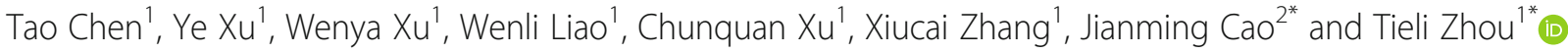

\begin{abstract}
Background: Pseudomonas aeruginosa is the most common Gram-negative pathogen responsible for chronic wound infections, such as diabetic foot infections, and further exacerbates the treatment options and cost of such conditions. Hypertonic glucose, a commonly used prolotherapy solution, can accelerate the proliferation of granulation tissue and improve microcirculation in wounds. However, the action of hypertonic glucose on bacterial pathogens that infect wounds is unclear. In this study, we investigated the inhibitory effects of hypertonic glucose on multidrug-resistant $P$. aeruginosa strains isolated from diabetic foot infections. Hypertonic glucose represents a novel approach to control chronic wound infections caused by $P$. aeruginosa.

Results: Four multidrug-resistant $P$. aeruginosa clinical strains isolated from diabetic foot ulcers from a tertiary hospital in China and the reference $P$. aeruginosa PAO1 strain were studied. Hypertonic glucose significantly inhibited the growth, biofilm formation, and swimming motility of $P$. aeruginosa clinical strains and PAO1. Furthermore, hypertonic glucose significantly reduced the production of pyocyanin and elastase virulence factors in $P$. aeruginosa. The expression of major quorum sensing genes (lasl, lasR, rhll, and $r h / R$ ) in $P$. aeruginosa were all downregulated in response to hypertonic glucose treatment. In a Galleria mellonella larvae infection model, the administration of hypertonic glucose was shown to increase the survival rates of larvae infected by $P$. aeruginosa strains (3/5).
\end{abstract}

Conclusions: Hypertonic glucose inhibited the growth, biofilm formation, and swimming motility of $P$. aeruginosa, as well as reduced the production of virulence factors and quorum sensing gene expression. Further studies that investigate hypertonic glucose therapy should be considered in treating chronic wound infections.

Keywords: Hypertonic glucose, Pseudomonas aeruginosa, Quorum sensing, Virulence factors, Biofilm, Motility

\section{Background}

Pseudomonas aeruginosa is an important human opportunistic pathogen that can cause life-threatening infections, particularly in immunocompromised patients. It is also the most common Gram-negative pathogen responsible for infections of chronic wounds, such as venous

\footnotetext{
*Correspondence: wzcjming@163.com; wyztli@163.com

${ }^{2}$ School of Laboratory Medicine and Life Sciences, Wenzhou Medical University, Wenzhou, Zhejiang Province, China

${ }^{1}$ Department of Clinical Laboratory, the First Affiliated Hospital of Wenzhou Medical University, Wenzhou, Zhejiang Province, China
}

leg ulcers, pressure ulcers, and diabetic foot ulcers [1-3]. Extensive use of antibiotics has created an evolutionary pressure on $P$. aeruginosa, which has led to high levels of multiple drug resistance (MDR). Therefore, rational strategies that minimize the probability for the emergence of antibiotic resistance are needed to combat pathogenic $P$. aeruginosa.

Hypertonic glucose, which is a commonly used prolotherapy solution [4], can accelerate the proliferation of granulation tissue and improve microcirculation within a wound, which reduces the patient's healing time and the

(c) The Author(s). 2020 Open Access This article is licensed under a Creative Commons Attribution 4.0 International License, which permits use, sharing, adaptation, distribution and reproduction in any medium or format, as long as you give appropriate credit to the original author(s) and the source, provide a link to the Creative Commons licence, and indicate if changes were made. The images or other third party material in this article are included in the article's Creative Commons licence, unless indicated otherwise in a credit line to the material. If material is not included in the article's Creative Commons licence and your intended use is not permitted by statutory regulation or exceeds the permitted use, you will need to obtain permission directly from the copyright holder. To view a copy of this licence, visit http://creativecommons.org/licenses/by/4.0/ The Creative Commons Public Domain Dedication waiver (http://creativecommons.org/publicdomain/zero/1.0/) applies to the data made available in this article, unless otherwise stated in a credit line to the data. 
requirement for further medical care [5]. The combined application of hypertonic glucose and negative pressure wound therapy was found to be safe and effective in preparing $P$. aeruginosa-infected wounds for grafting [6]. However, despite several reports indicating that hypertonic glucose is an effective therapy for chronic wound injuries, less is known regarding the actions of hypertonic glucose in the treatment of bacterial wound infections.

The pathogenicity of $P$. aeruginosa is influenced by processes such as biofilm formation, motility, and virulence factors such as pyocyanin and elastase [7-9]. These factors are regulated by quorum sensing (QS), which is a cell-cell communication system that monitors bacterial population density and coordinates physiological processes accordingly $[10,11]$. $P$. aeruginosa has three QS systems, termed las, rhl, and pqs [12]. LasI, RhlI, and PqsA are responsible for the biosynthesis of signal molecules $\mathrm{N}$-(3-oxododecanoyl)-L-homoserine lactone (OdDHL), N-butyrylhomoserine lactone (BHL), and Pseudomonas quinolone signal (PQS), respectively [2]. The corresponding receptors for the signal molecules are LasR, RhlR, and PqsR, respectively. Specific autoinducer binding to its receptor can activate genes responsible for pathogenic phenotypes of $P$. aeruginosa [13]. Therefore, utilization of anti-QS strategies presents a potential approach to prevent and treat $P$. aeruginosa infections.

In this study, we investigated the antimicrobial and anti-quorum sensing function of hypertonic glucose on $P$. aeruginosa $\mathrm{PAO} 1$ and four multidrug-resistant $P$. aeruginosa clinical strains isolated from diabetic foot ulcers, to offer new insights in chronic wound infection treatment.

\section{Results}

\section{Antimicrobial susceptibility profiles and antimicrobial} activity of hypertonic glucose

Antibiotic resistance profiles of four multidrug-resistant $P$. aeruginosa strains are displayed in Table 1 . All isolates showed resistance to tobramycin, gentamicin, and

Table 1 Summary of antibiotic resistance profiles of multidrugresistant Pseudomonas aeruginosa

\begin{tabular}{lllllllllllll}
\hline Strains & \multicolumn{11}{ll}{ Antimicrobial resistance } \\
\cline { 2 - 10 } & AMK & TOB & GEN & CAZ & FEP & ATM & IPM & TZP & SCF & CIP & LVX \\
\hline TL2941 & S & R & R & I & I & R & I & R & I & R & R \\
TL3147 & R & R & R & S & R & R & S & R & I & R & I \\
TL3445 & S & R & R & R & R & N & R & I & S & R & R \\
TL3581 & R & R & R & S & R & N & S & R & I & R & R
\end{tabular}

AMK Amikacin, TOB Tobramycin, GEN Gentamicin, CAZ ceftazidime, FEP Cefepime, ATM Aztreonam, IPM imipenem, TZP Piperacillin-tazobactam, SCF Cefoperazone-sulbactam, CIP ciprofloxacin, LVX Levofloxacin, $S$ susceptible, $R$ resistant, I intermediate, $N$ Not done ciprofloxacin. The broth micro-dilution method was used to determine the MICs of glucose against different strains. As shown in Table 2, glucose inhibited the growth of all the $P$. aeruginosa strains (PAO1, TL2941, TL3147, TL3445 and TL3581) at a concentration of 300 $\mathrm{mg} / \mathrm{mL}$. In addition, hypertonic glucose showed a concentration-dependent inhibitory effect on the growth of all $P$. aeruginosa strains at a concentration of at least $50 \mathrm{mg} / \mathrm{mL}(P<0.05)$ (Fig. 1$)$.

\section{Hypertonic glucose inhibits biofilm formation and swimming motility of $P$. aeruginosa}

The effects of hypertonic glucose on biofilm formation were studied in $P$. aeruginosa using a crystal violet assay. Hypertonic glucose at a concentration of $50 \mathrm{mg} / \mathrm{mL}$ caused almost $50 \%$ reduction in the biofilm-forming capacity of all tested $P$. aeruginosa isolates $(P<0.05)$ (Fig. 2). Furthermore, hypertonic glucose showed a concentration-dependent inhibitory effect on the swimming motility of all $P$. aeruginosa strains $(P<0.05)$ (Fig. 3). In media containing $300 \mathrm{mg} / \mathrm{mL}$ glucose, a circular turbid zone was not observed, demonstrating that motility was completely inhibited at this concentration.

\section{Hypertonic glucose inhibits virulence factor production}

The effects of hypertonic glucose on virulence factors such as elastase and pyocyanin were also examined. Hypertonic glucose significantly inhibited the production of elastase and pyocyanin in P. aeruginosa PAO1 and strains TL2941, TL3147, and TL3445 at all tested concentrations (Fig. 4). A glucose concentration of $100 \mathrm{mg} /$ $\mathrm{mL}$ caused at least $80 \%$ reduction in the production of pyocyanin and elastase $(P<0.05)$. In $P$. aeruginosa strain TL3581, the production of pyocyanin was reduced similarly upon hypertonic glucose treatment. However, due to the low levels of elastase produced by TL3581 even in the absence of glucose, which could not be detected by the Elastin-Congo red method, the percentage inhibition rate could not be measured.

Hypertonic glucose regulates QS-related gene expression We next investigated the effect of hypertonic glucose on the expression of QS-related genes, which are commonly

Table 2 Minimum inhibitory concentrations of glucose against MDR Pseudomonas aeruginosa clinical isolates and PAO1

\begin{tabular}{lll}
\hline & Strains & Glucose MIC values $(\mathrm{mg} / \mathrm{ml})$ \\
\hline MDR clinical isolates & TL2941 & 300 \\
& TL3147 & 300 \\
& TL3445 & 300 \\
& TL3581 & 300 \\
Reference isolates & PAO1 & 300
\end{tabular}




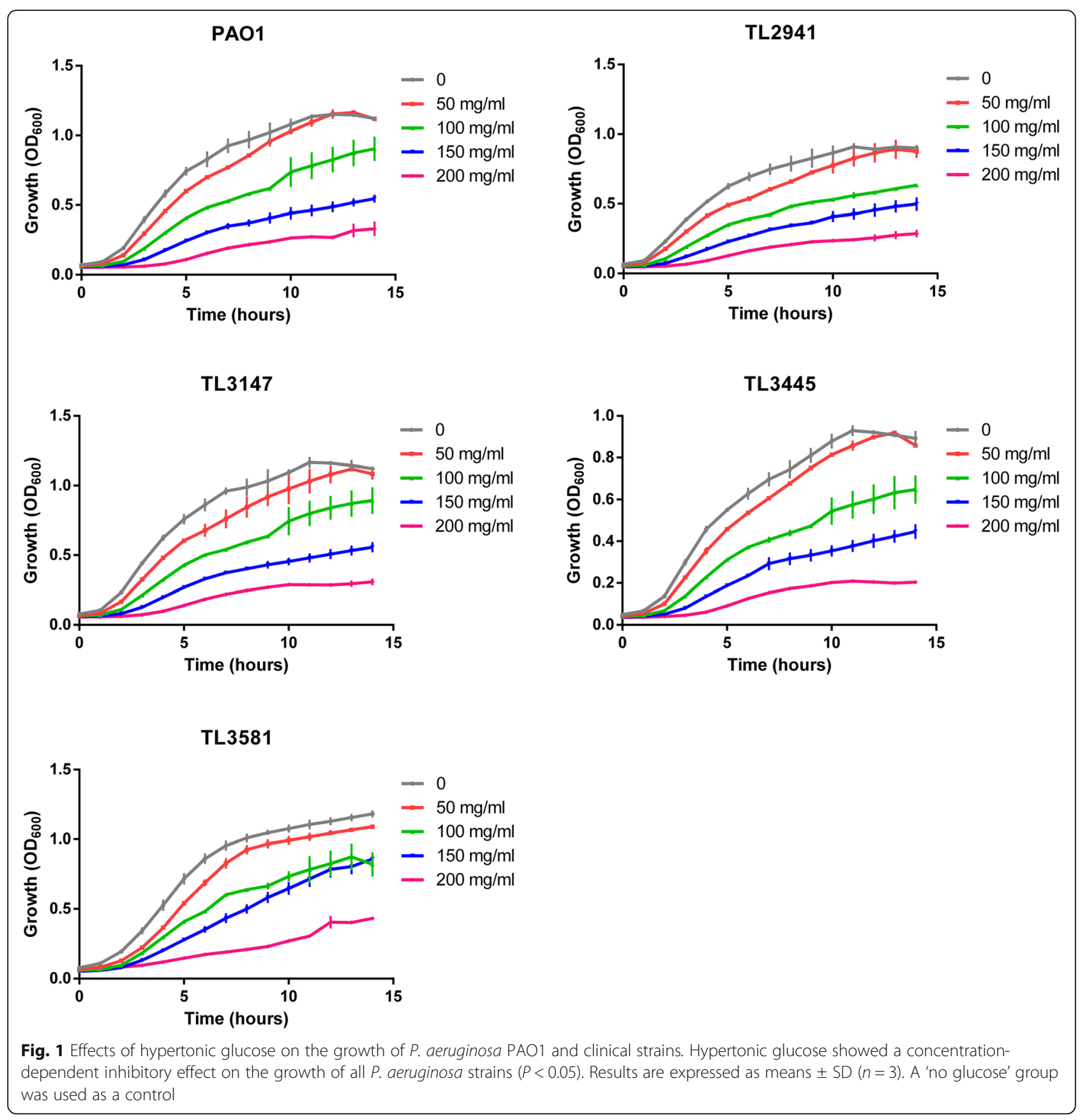

associated with the regulation of virulence gene expression and biofilm formation. Therefore, we evaluated the expression of QS-regulated genes in P. aeruginosa in response to exposure to hypertonic glucose. The relative expression of genes lasI, lasR, rhlI, and rhlR in P. aeruginosa PAO1 and multidrug-resistant strains were determined from calculated $\mathrm{Ct}$ values. As shown in Fig. 5, QS-related genes expressions showed at least one-fold reduction in all tested $P$. aeruginosa strains under 200 $\mathrm{mg} / \mathrm{mL}$ hypertonic glucose conditions $(P<0.05)$. Moreover, the relative expressions of genes belonging to the rhl regulatory system was lower compared to the las regulatory system in $P$. aeruginosa strains except for TL3147.

Hypertonic glucose reduces mortality in G. mellonella larvae infection model

To investigate the effect of hypertonic glucose on virulence, an in vivo G. mellonella infection model was used. All $P$. aeruginosa isolates caused a lethal infection in the larvae (Fig. 6). Following the administration of $200 \mathrm{mg} /$ mLglucose, the survival rates of larvae infected by $P$. 
PA01

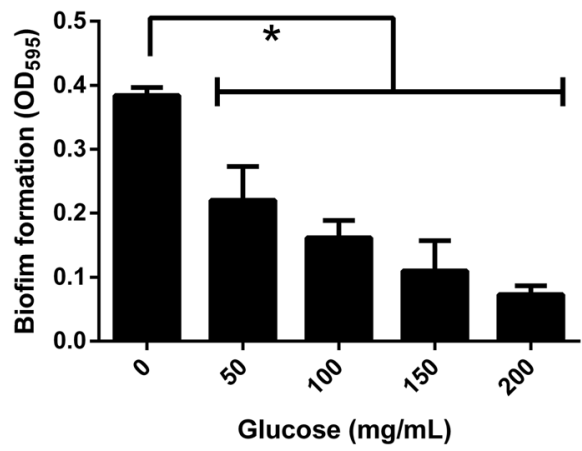

TL3147

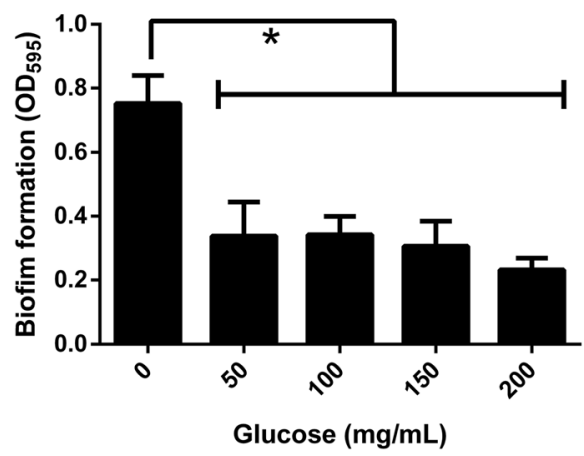

TL3581

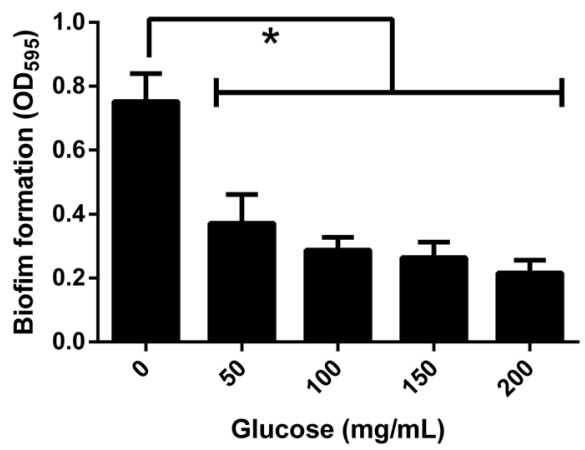

TL2941

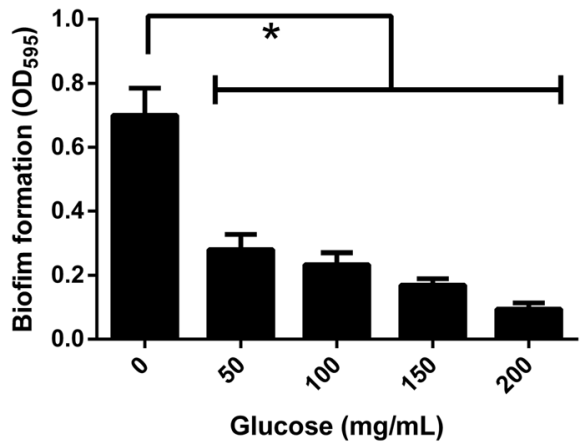

TL3445

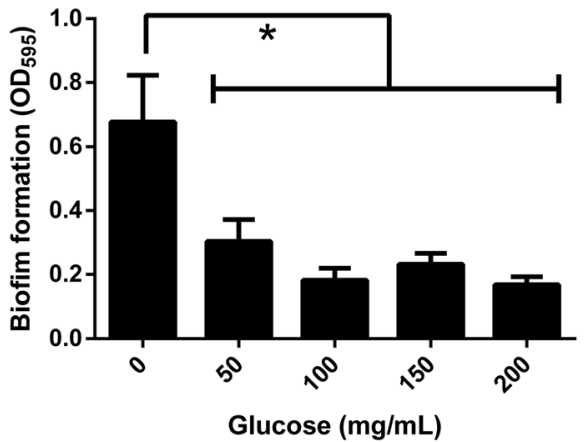

Fig. 2 Effects of hypertonic glucose on biofilm formation of $P$. aeruginosa. Hypertonic glucose decreased the biofilm-forming capacity of all tested $P$. aeruginosa. Results are expressed as means \pm SD $(n=3)$. * represents $P<0.05$. A 'no glucose' group was used as a control

aeruginosa isolates (PAO1, TL3147, TL3445) were enhanced $(P<0.05)$. For $P$. aeruginosa strains TL2941 and TL3581, though the survival rates of larvae slightly increased, no significant difference in mortality was displayed after the administration of $200 \mathrm{mg} / \mathrm{mL}$ glucose $(P>0.05)$.

\section{Discussion}

$P$. aeruginosa is among the top three major human opportunistic pathogens that cause mortality and morbidity in immunocompromised patients, and is a common cause of chronic wound infections, such as diabetic foot infections [14] and leg ulcers [15]. P. aeruginosa has acquired high levels of drug resistance from the widespread use of antibiotics, and new treatment approaches are urgently needed. Hypertonic glucose is a commonly used prolotherapy solution that can reduce healing times; however, it is unclear how hypertonic glucose acts to reduce bacterial virulence associated with wound infections. To date, this is the first study investigating the effects of hypertonic glucose on $P$. aeruginosa.

In this study, we demonstrated that hypertonic glucose had an inhibitory effect on the growth of $P$. aeruginosa PAO1 and four clinical strains at a concentration of 

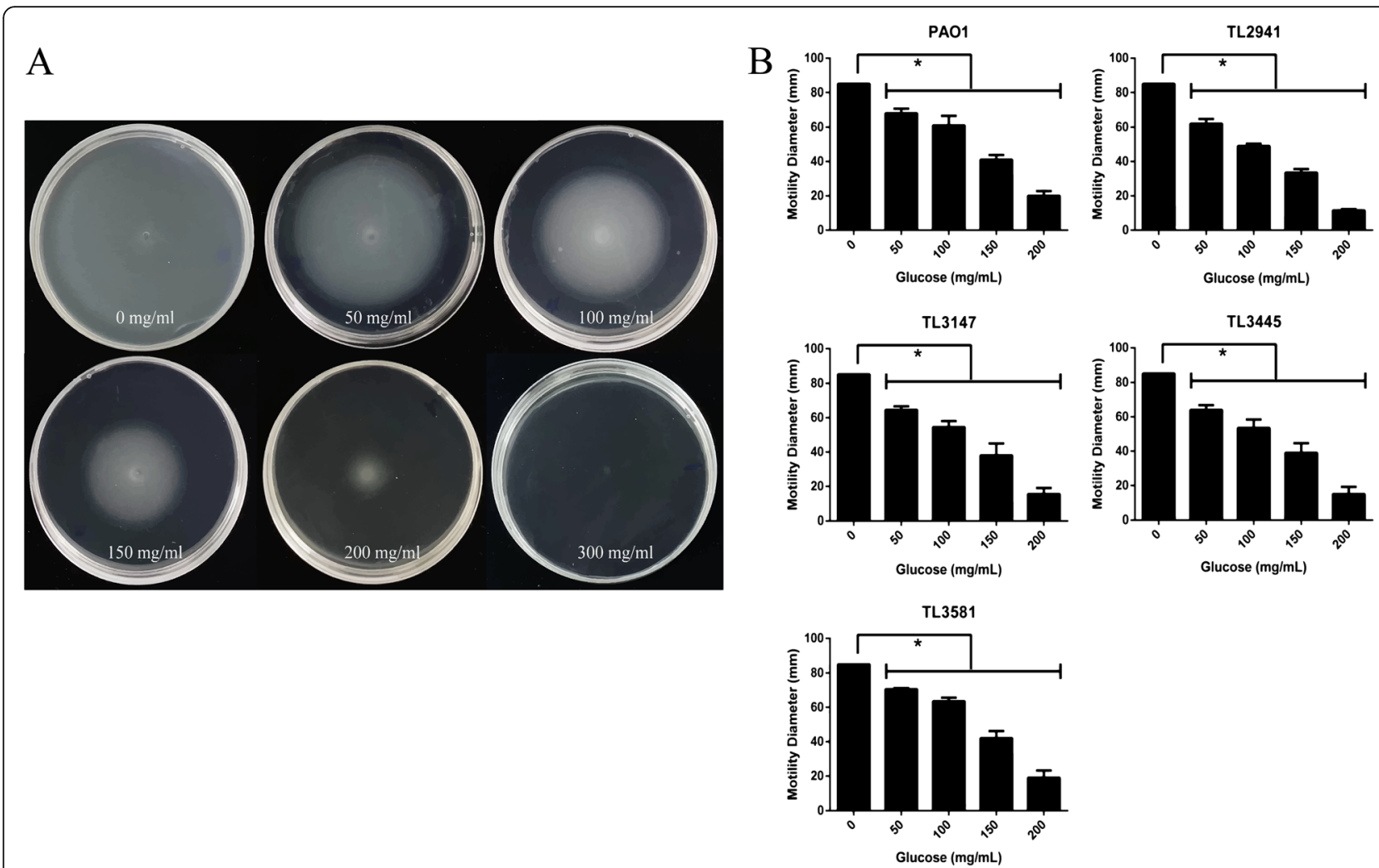

Fig. 3 Effects of hypertonic glucose on the swimming motility of $P$. aeruginosa strains $(P<0.05)$ a: Swimming agar containing a series of concentrations of hypertonic glucose $(0,50,100,150,200$ and $300 \mathrm{mg} / \mathrm{mL}$ ) inoculated with PAO1. (Image A was spliced with six swimming agar pictures) b: Average diameter of the bacterial colony. Results are expressed as means $\pm \mathrm{SD}(n=3) .{ }^{*}$ represents $P<0.05$. A 'no glucose' group was used as a control

more than $50 \mathrm{mg} / \mathrm{mL}$. We further explored the actions of glucose activity against $P$. aeruginosa at sub-MICs. The pathogenesis of $P$. aeruginosa relies largely on motility and the production of virulence factors such as pyocyanin and elastase, which are controlled by QS systems [16]. We observed that hypertonic glucose significantly inhibited swimming motility in a concentrationdependent manner and reduced the production of pyocyanin and elastase by over $80 \%$ when used at a concentration of $100 \mathrm{mg} / \mathrm{mL}$, which demonstrated a potential role of hypertonic glucose to reduce $P$. aeruginosa virulence. It is known that $P$. aeruginosa frequently forms biofilms on medical surfaces and is associated with chronic wound infections. Such biofilms are highly refractory to removal and resistant to antimicrobials, and their presence is generally correlated with poor treatment outcomes $[17,18]$. This study revealed that biofilm formation of all tested $P$. aeruginosa strains was attenuated in the presence of hypertonic glucose.

Targeting QS systems represents an attractive option for infection control, which could minimize selection pressures and the risk of drug resistance. In this work, we investigated whether the expressions of major QSregulated genes lasI, lasR, rhlI, and rhlR could be influenced by hypertonic glucose treatment to attenuate $P$. aeruginosa virulence factors. We showed that hypertonic glucose treatment significantly reduced the expression of lasI, lasR, rhlI, and rhlR genes $(P<0.05)$. In the las and rhl systems, the virulence factors of $P$. aeruginosa are primarily encoded by QS-regulated genes lasI, lasR, rhlI, and rhlR [16]. The lasI and rhlI genes are required for the synthesis of QS signals, which are capable of binding to the transcriptional regulator LasR and RhlR, respectively. It is known that LasR and RhlR interacting with the corresponding signals can trigger the production of pyocyanin and elastase in $P$. aeruginosa [19]. In this study, the significantly decreased expression of QS-regulated genes correlated with a decrease in virulence factor production. A qRT-PCR experiment showed that the relative expression of genes belonging to the $r h l$ regulatory system was reduced more than the las regulatory system in $P$. aeruginosa strains, except TL3147 (Fig. 5). This was an interesting finding, which indicates that the $r h l$ regulatory system might be more sensitive to hypertonic glucose treatment. Further studies are required to identify the mechanisms involved.

We used a G. mellonella infection model to explore the anti-virulence ability of hypertonic glucose in vivo. 


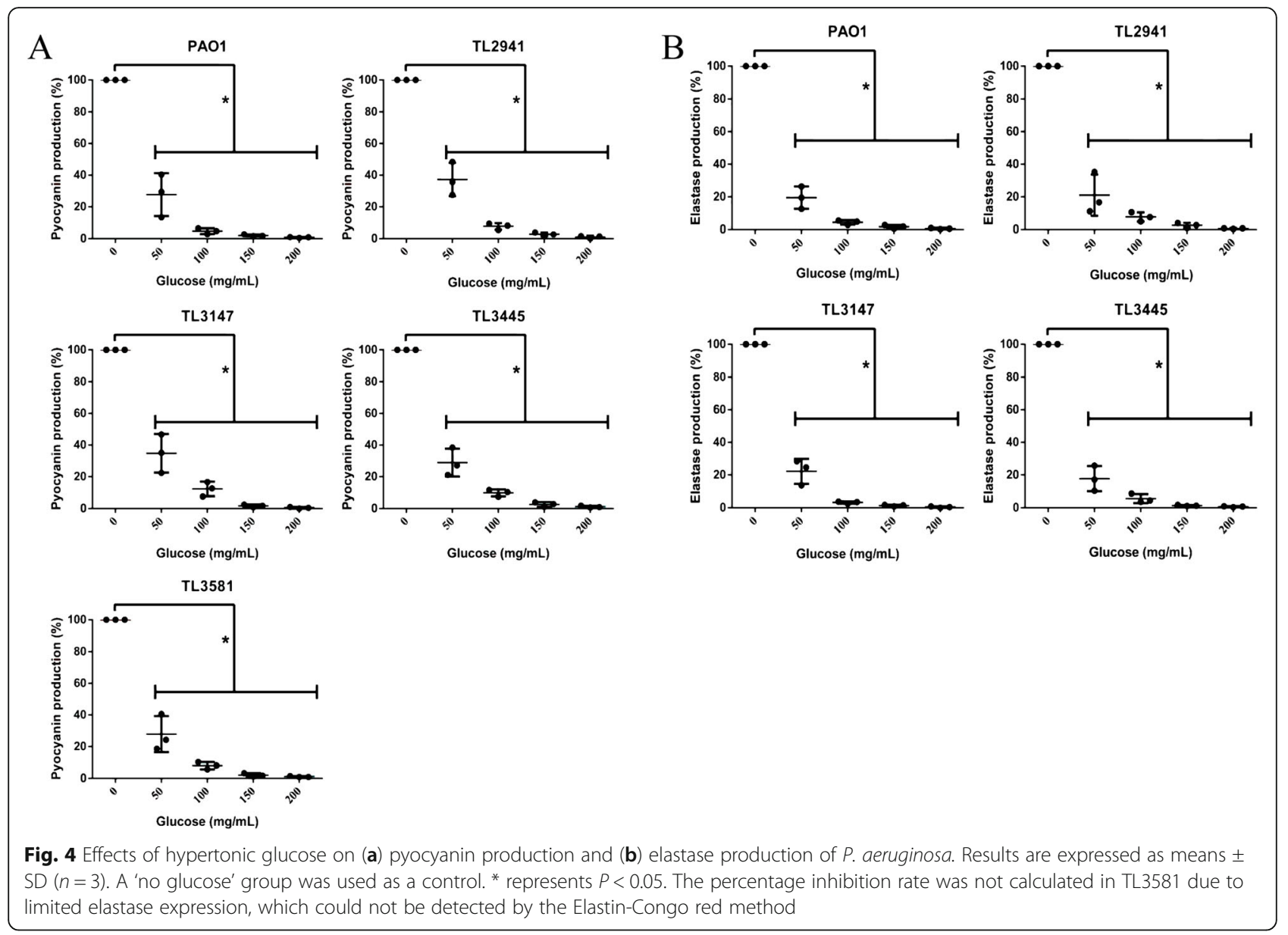

The results showed hypertonic glucose reduced the mortality in G. mellonella larvae infection model for a majority of strains (PAO1, TL3147, and TL3445). However, no significant change in mortality of G. mellonella larvae was observed with the administration of hypertonic glucose for other two isolates (TL2941 and TL3581). It is possible that once the in vivo levels of hypertonic glucose drop below a certain threshold, the growth inhibition and virulence factor expression of $P$. aeruginosa is rapidly alleviated, and its pathogenicity restored. The reason for the differences between strains will be further explored.

It is known that QS systems play an important role in wound infections [20]. The exploitation of QS systems to search for virulence factor inhibitors has offered an alternative opportunity to control bacterial infections, given the fact that traditional antimicrobial treatments can easily become ineffective due to bacterial resistance. QS inhibitors have been shown to greatly impair bacterial infections, especially in the control of biofilm-related diseases $[21,22]$. We showed here that hypertonic glucose could inhibit growth, attenuate virulence factors, and regulate quorum sensing of multidrug-resistant $P$. aeruginosa. Based on this notion, further strategies involving hypertonic glucose should be considered to enhance the therapeutic effect of treatments to combat bacterial infections.

\section{Conclusions}

In conclusion, to the best of our knowledge, this is the first study to report the inhibitory effects of hypertonic glucose on $P$. aeruginosa. Hypertonic glucose displayed the ability to inhibit growth, biofilm formation, and swimming motility as well as attenuate virulence factors of $P$. aeruginosa. A reduced expression of genes involved in quorum sensing correlated with attenuated virulence factors. Future studies that investigate the activity of hypertonic glucose should be considered in wound infection management.

\section{Methods}

\section{Bacterial strains}

$P$. aeruginosa strain $\mathrm{PAO} 1$, and four multidrug-resistant $P$. aeruginosa strains (TL2941, TL3147, TL3445 and TL3581) isolated from different diabetic foot ulcers from patients at the First Affiliated Hospital of Wenzhou 
PA01

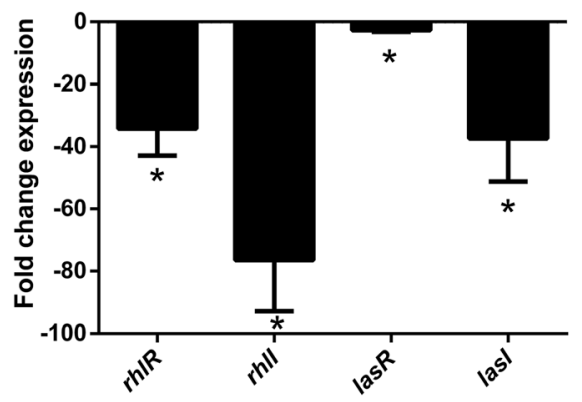

TL3147

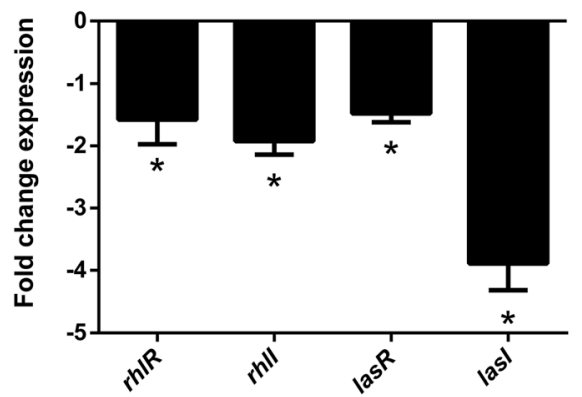

TL3581

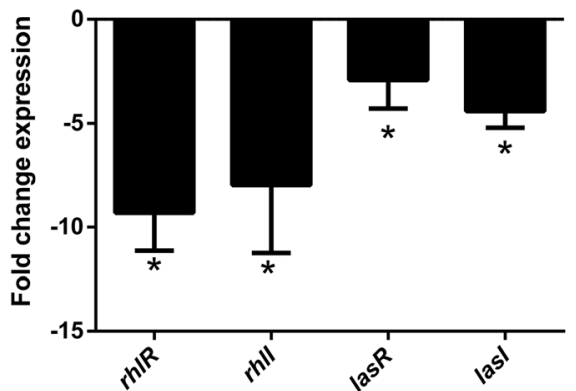

TL2941

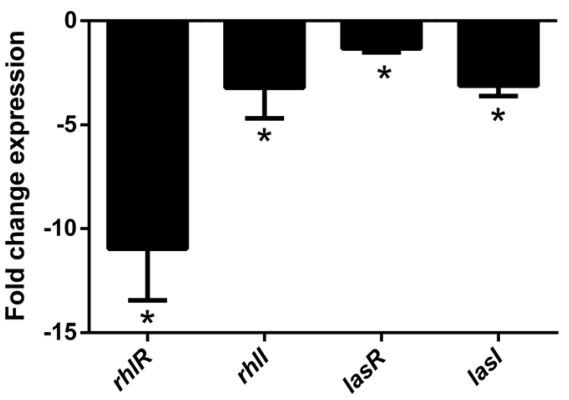

TL3445

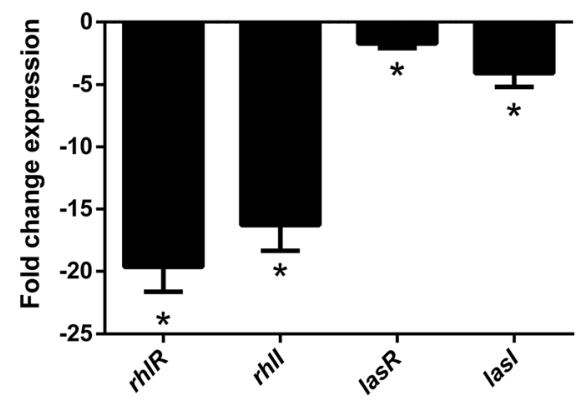

Fig. 5 Effects of hypertonic glucose on QS-related gene expression in P. aeruginosa. Average relative amounts of tested genes were normalized to the average relative amount of the rps $L$ reference gene. Results are expressed as means $\pm S D(n=3)$. A 'no glucose' group was used as a control. * represents $P<0.05$

Medical University in China were used in this study. Identification and antimicrobial susceptibility testing were conducted on clinical isolates using the VITEK MS and VITEK2 systems, respectively. All strains were cultured in $\mathrm{LB}$ medium ( $1 \%$ tryptone, $1.0 \% \mathrm{NaCl}, 0.5 \%$ yeast extract) at $37^{\circ} \mathrm{C}$.

\section{Minimum inhibitory concentration assay}

The minimum inhibitory concentration (MIC) values of glucose (D-(+)-glucose; Sigma, St. Louis, USA) were determined using previously published methods, with some modifications [23]. Briefly, bacterial suspensions $\left(10^{8}\right.$ $\mathrm{CFU} / \mathrm{mL}$ ) of $P$. aeruginosa PAO1 and multidrugresistant $P$. aeruginosa strains were added to LB broth
$(1 \%, \mathrm{v} / \mathrm{v})$ that contained glucose at concentrations of $(0$, 50, 100, 150, 200, 250, 300 and $350 \mathrm{mg} / \mathrm{mL}$ ) in 96-well microtiter plates, and then incubated at $37^{\circ} \mathrm{C}$ for $18 \mathrm{~h}$. The MIC was the lowest glucose concentration that caused complete inhibition of cell growth. All further experiments in this study used sub-minimum inhibitory concentrations (sub-MICs) of glucose.

\section{Growth curve assay}

The effects of glucose on the growth rate of $P$. aeruginosa strains were determined according to a method described previously, with some modifications [24]. Briefly, overnight cultures were diluted 1:100 into fresh LB broth and incubated at $37^{\circ} \mathrm{C}$ for $4 \mathrm{~h}$ before adjusting the 
PA01

TL3147

TL3581

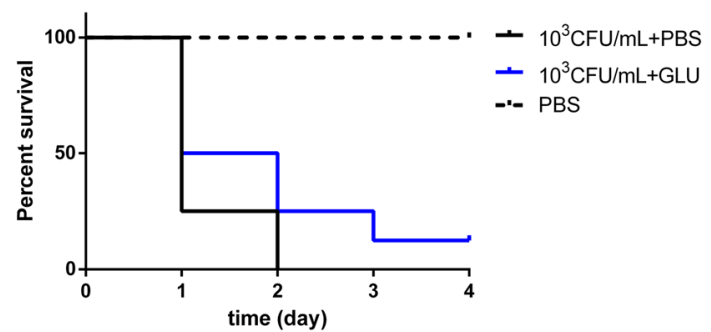

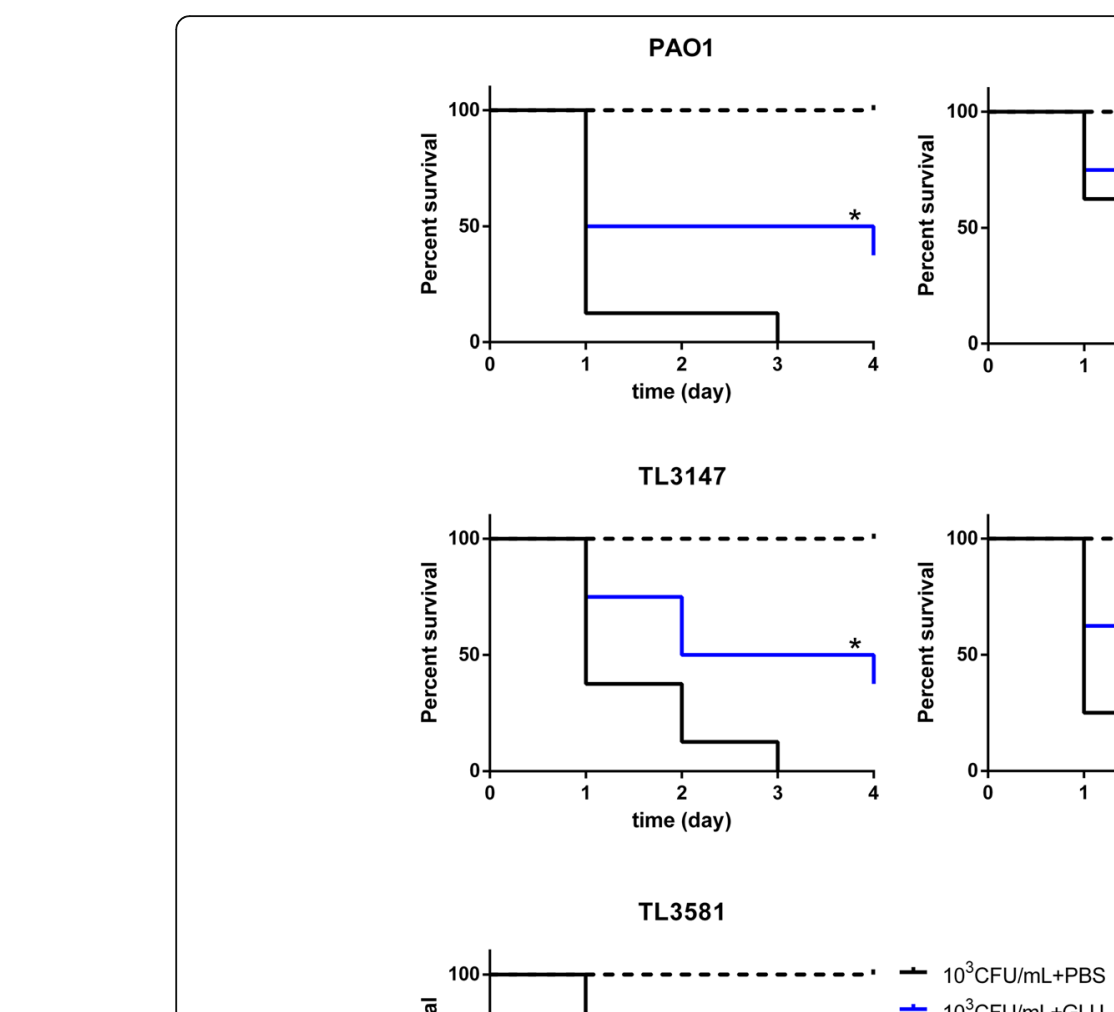

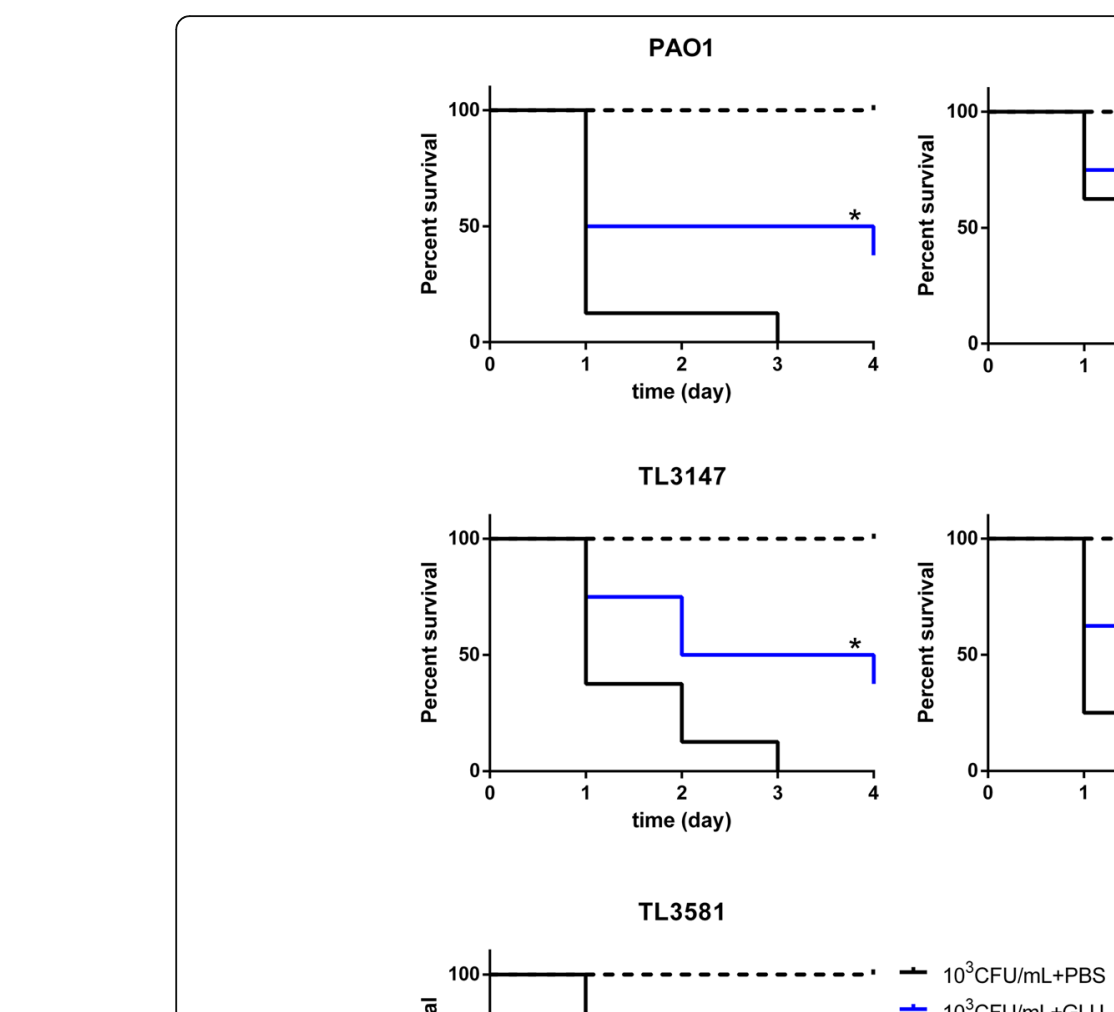

TL2941

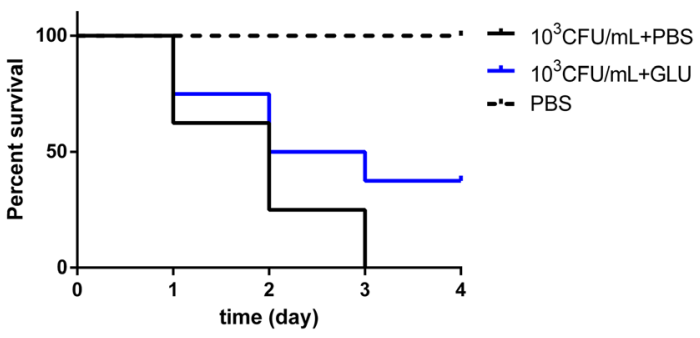

TL3445

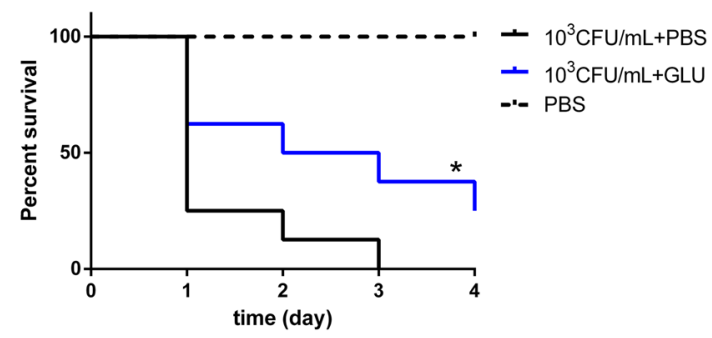




\section{Pyocyanin assay}

Pyocyanin production was examined as described previously with modifications [25]. Bacterial cultures containing different concentrations of glucose $(0,50,100,150$ and $200 \mathrm{mg} / \mathrm{mL}$ ) were grown for $17 \mathrm{~h}$, and $1 \mathrm{~mL}$ samples were then centrifuged at $13,000 \mathrm{rpm}$ for $5 \mathrm{~min}$. The supernatant was collected and extracted with $600 \mu \mathrm{L}$ chloroform, and then mixed by vortex $(2 \times 10 \mathrm{~s})$. After centrifugation at $13,000 \mathrm{rpm}$ for $5 \mathrm{~min}$, the chloroform phase was transferred to a sterile tube and mixed with $0.5 \mathrm{~mL}$ of $0.2 \mathrm{M} \mathrm{HCl}$ followed by gentle shaking to transfer the pyocyanin to the aqueous phase. Pyocyanin was determined by measuring the absorbance of the aqueous phase at $\mathrm{OD}_{510}$.

\section{Elastase activity assay}

The elastolytic activity of the cell-free culture supernatant of $P$. aeruginosa was determined using Elastin-Congo red (ECR; Sigma) as the substrate [26]. $100 \mu \mathrm{L}$ supernatants of $P$. aeruginosa incubated in different concentrations of glucose $(0,50,100,150$ and $200 \mathrm{mg} / \mathrm{mL})$ for $17 \mathrm{~h}$ were added to $900 \mu \mathrm{L}$ of ECR buffer ( $100 \mathrm{mM}$ Tris, $1 \mathrm{mM} \mathrm{CaCl}_{2}, \mathrm{pH}$ 7.5) containing $10 \mathrm{mg}$ of ECR and incubated at $37^{\circ} \mathrm{C}$ for $3 \mathrm{~h}$. The reaction was terminated by adding $1 \mathrm{~mL}$ of $0.7 \mathrm{M}$ sodium phosphate buffer ( $\mathrm{pH}$ 6.0) and the tubes were placed in a cold water-bath. The insoluble ECR was removed by centrifugation at $10,000 \mathrm{rpm}$ for $10 \mathrm{~min}$, and the absorbance was measured at $\mathrm{OD}_{495}$.

\section{Galleria mellonella larvae infection model}

G. mellonella killing assays were performed as described previously, with some modifications [27]. Eight larvae weighing between 200 and $250 \mathrm{mg}$ were randomly selected for each $P$. aeruginosa strain. Overnight bacterial cultures were diluted 1:100 in fresh LB broth and incubated at $37^{\circ} \mathrm{C}$ for $4 \mathrm{~h}$. Cell suspensions were washed three times with phosphate-buffered saline (PBS) and resuspended in PBS to $10^{3} \mathrm{CFU} / \mathrm{mL}$. A $10 \mu \mathrm{L}$ of bacterial suspension $\left(10^{3} \mathrm{CFU} / \mathrm{mL}\right)$ was injected into the last left proleg using a $25 \mu \mathrm{L}$ Hamilton precision syringe and a $10 \mu \mathrm{L}$ of glucose at $200 \mathrm{mg} / \mathrm{mL}$ (or a $10 \mu \mathrm{L}$ of PBS as a control) was injected into the last right-side proleg at $2 \mathrm{~h}$ post infection. Larvae injected with $10 \mu \mathrm{l}$ PBS were used as controls. G. mellonella were incubated at $37^{\circ} \mathrm{C}$ in the dark and observed after $24 \mathrm{~h}, 48 \mathrm{~h}, 72 \mathrm{~h}$ and $96 \mathrm{~h}$. Larvae were considered dead when they repeatedly failed to respond to physical stimuli. The primary outcome for the insect model was rapidity and extent of mortality of $G$. mellonella, as assessed with Kaplan-Meier analysis and a log-rank test.

\section{Quantitative reverse transcription PCR}

The effects of hypertonic glucose on the expression levels of $P$. aeruginosa major QS circuit genes (lasI, lasR, rhll, and $r h l R)$ were evaluated using quantitative reverse transcription PCR (qRT-PCR). RNA was extracted from $P$. aeruginosa isolates that were grown in fresh $\mathrm{LB}$ medium with or without $200 \mathrm{mg} / \mathrm{mL}$ glucose at $37^{\circ} \mathrm{C}$ for $17 \mathrm{~h}$. Total RNA was extracted from planktonic bacteria using an RNeasy Mini Kit (Qiagen, Valencia, CA, USA) according to the manufacturer's instructions. The extracted RNA samples were stored at $-80^{\circ} \mathrm{C}$. Purified RNA was reverse transcribed into cDNA using a cDNA Synthesis Kit (TaKaRa, Tokyo, Japan) according to the manufacturer's instructions. Gene expression levels were measured with qRT-PCR using a 7500 RT-PGE system (TOYOBO, Osaka, Japan) and a SYBR Green qRT-PCR Kit (TOYOBO) with specific primers listed in Additional Table S1. The rpsL gene was used as an internal control to normalize the data. Gene expression levels were calculated using the $2^{-\Delta \Delta \mathrm{Ct}}$ method.

\section{Statistical analysis}

All experiments were conducted independently with at least three replicates on different days, and results were expressed as mean \pm standard deviation. The total area under the curve was calculated for the growth rate analysis. The results of the pyocyanin and elastase assays are presented as production percentage of the untreated $(0 \mathrm{mg} / \mathrm{ml})$ samples. A T-test was used to evaluate the significance of differences between two groups. One-way analysis of variance (ANOVA) was performed to analyze the significance among more than two groups. Statistical significance was determined at $P<0.05$. Statistical analyses were performed using SPSS version 17.0 statistical software.

\section{Supplementary information}

Supplementary information accompanies this paper at https://doi.org/10 1186/s12866-020-01889-2.

Additional file 1:. Additional Table S

\section{Abbreviations}

qRT-PCR: Quantitative Reverse Transcription Polymerase Chain Reaction QS: Quorum sensing; OdDHL: N-(3-oxododecanoyl)-L-homoserine lactone; $\mathrm{BHL}$ : N-butyrylhomoserine lactone; PQS: Pseudomonas quinolone signal

\section{Acknowledgments}

The authors want to give thanks to Dr. Jonathan Wilksch from Monash University for his help in paper writing.

\section{Authors' contributions}

All authors contributed to the conception and design of the study; TC, YX, WX,WL, CX and XZ acquired the data; TC performed the statistical analysis; TC wrote the first draft of the manuscript; JC and TZ supervised the study. All authors contributed to manuscript revision, read and approved the submitted version

\section{Funding}

The work was financially supported by a grant from the Zhejiang Province Natural Science Foundation of China (No. LY18H190004) and the Health Department of Zhejiang Province of the People's Republic of China (No. 2018KY123). These two funding bodies provided funds for the purchase of 
consumption materials for the study but had no role in the design of the study and collection, analysis, and interpretation of data and writing of the manuscript.

\section{Availability of data and materials}

The datasets used and analyzed during the study are available from the corresponding author on reasonable request.

\section{Ethics approval and consent to participate}

Ethics approval and consent were deemed unnecessary in this research, according to the Ethics Committee of the First Affiliated Hospital of Wenzhou Medical University.

\section{Consent for publication}

Not applicable.

\section{Competing interests}

The authors declare that they have no competing interests.

Received: 16 January 2020 Accepted: 1 July 2020

Published online: 09 July 2020

\section{References}

1. Lu J, Cokcetin NN, Burke CM, Turnbull L, Liu M, Carter DA, et al. Honey can inhibit and eliminate biofilms produced by Pseudomonas aeruginosa. Sci Rep. 2019:9:18160

2. Lee J, Zhang L. The hierarchy quorum sensing network in Pseudomonas aeruginosa. Protein Cell. 2015;6:26-41.

3. Malekian A, Esmaeeli Djavid G, Akbarzadeh K, Soltandallal M, Rassi Y, Rafinejad J, et al. Efficacy of maggot therapy on Staphylococcus aureus and Pseudomonas aeruginosa in diabetic foot ulcers: a randomized controlled trial. J Wound Ostomy Continence Nurs. 2019;46:25-9.

4. Rabago D, Zgierska A, Fortney L, Kijowski R, Mundt M, Ryan M, et al. Hypertonic dextrose injections (prolotherapy) for knee osteoarthritis: results of a single-arm uncontrolled study with 1-year follow-up. J Altern Complement Med. 2012;18:408-14.

5. Zhou DP, Lu LQ, Mao XL. Insulin and hyperosmotic glucose solution external used for treating pressure sore. Hunan Yi Ke Da Xue Xue Bao. 2001; 26:475-6.

6. Zhao J-C, Xian C-J, Yu J-A, Shi K, Hong L. Hypertonic glucose combined with negative pressure wound therapy to prepare wounds with Pseudomonas aeruginosa infection for skin grafting: a report of 3 cases. Ostomy Wound Manage. 2015;61:28-44.

7. Wu H, Moser C, Wang H-Z, Høiby N, Song Z-J. Strategies for combating bacterial biofilm infections. Int J Oral Sci. 2015;7:1-7.

8. Crousilles A, Maunders E, Bartlett S, Fan C, Ukor E-F, Abdelhamid Y, et al. Which microbial factors really are important in Pseudomonas aeruginosa infections? Future Microbiol. 2015:10:1825-36.

9. Allen RC, Popat R, Diggle SP, Brown SP. Targeting virulence: can we make evolution-proof drugs? Nat Rev Microbiol. 2014;12:300-8.

10. Sheng J-Y, Chen T-T, Tan X-J, Chen T, Jia A-Q. The quorum-sensing inhibiting effects of stilbenoids and their potential structure-activity relationship. Bioorg Med Chem Lett. 2015;25:5217-20.

11. Whiteley M, Diggle SP, Greenberg EP. Progress in and promise of bacterial quorum sensing research. Nature. 2017:551:313-20.

12. Zhou J, Bi S, Chen H, Chen T, Yang R, Li M, et al. Anti-biofilm and Antivirulence activities of metabolites from Plectosphaerella cucumerina against Pseudomonas aeruginosa. Front Microbiol. 2017;8:769.

13. Papenfort K, Bassler BL. Quorum sensing signal-response systems in gramnegative bacteria. Nat Rev Microbiol. 2016;14:576-88.

14. Ramakant P, Verma AK, Misra R, Prasad KN, Chand G, Mishra A, et al. Changing microbiological profile of pathogenic bacteria in diabetic foot infections: time for a rethink on which empirical therapy to choose? Diabetologia. 2011;54:58-64.

15. Gjodsbol K, Christensen JJ, Karlsmark T, Jorgensen B, Klein BM, Krogfelt KA. Multiple bacterial species reside in chronic wounds: a longitudinal study. Int Wound J. 2006;3:225-31.

16. Castillo-Juarez I, López-Jácome LE, Soberón-Chávez G, Tomás M, Lee J, Castañeda-Tamez $P$, et al. Exploiting quorum sensing inhibition for the control of Pseudomonas Aeruginosa and Acinetobacter Baumannii biofilms. Curr Top Med Chem. 2017;17:1915-27.
17. Singh PK, Schaefer AL, Parsek MR, Moninger TO, Welsh MJ, Greenberg EP. Quorum-sensing signals indicate that cystic fibrosis lungs are infected with bacterial biofilms. Nature. 2000;407:762-4.

18. Weldrick PJ, Hardman MJ, Paunov VN. Enhanced clearing of wound-related pathogenic bacterial biofilms using protease-functionalized antibiotic Nanocarriers. ACS Appl Mater Interfaces. 2019;11:43902-19.

19. Vandeputte OM, Kiendrebeogo M, Rasamiravaka T, Stévigny C, Duez P, Rajaonson $\mathrm{S}$, et al. The flavanone naringenin reduces the production of quorum sensing-controlled virulence factors in Pseudomonas aeruginosa PAO1. Microbiology. 2011;157:2120-32.

20. Rumbaugh KP, Griswold JA, Iglewski BH, Hamood AN. Contribution of quorum sensing to the virulence of Pseudomonas aeruginosa in burn wound infections. Infect Immun. 1999:67:5854-62.

21. You R, Sun H, Yu Y, Lin Z, Qin M, Liu Y. Time-dependent hormesis of chemical mixtures: a case study on sulfa antibiotics and a quorum-sensing inhibitor of Vibrio fischeri. Environ Toxicol Pharmacol. 2016;41:45-53.

22. Furiga A, Lajoie B, El Hage S, Baziard G, Roques C. Impairment of Pseudomonas aeruginosa biofilm resistance to antibiotics by combining the drugs with a new quorum-sensing inhibitor. Antimicrob Agents Chemother. 2015;60:1676-86.

23. Yang $R$, Guan $Y$, Zhou J, Sun B, Wang Z, Chen H, et al. Phytochemicals from Camellia nitidissima chi flowers reduce the Pyocyanin production and motility of Pseudomonas aeruginosa PAO1. Front Microbiol. 2017;8:2640.

24. Wang H, Chu W, Ye C, Gaeta B, Tao H, Wang M, et al. Chlorogenic acid attenuates virulence factors and pathogenicity of Pseudomonas aeruginosa by regulating quorum sensing. Appl Microbiol Biotechnol. 2019;103:903-15.

25. Cao H, Xia T, Li Y, Xu Z, Bougouffa S, Lo YK, et al. Uncoupled quorum sensing modulates the interplay of virulence and resistance in a multidrugresistant clinical Pseudomonas aeruginosa isolate belonging to the MLST550 clonal complex. Antimicrob Agents Chemother. 2019;63:e01944-18.

26. Das MC, Sandhu P, Gupta P, Rudrapaul P, De UC, Tribedi P, et al. Attenuation of Pseudomonas aeruginosa biofilm formation by Vitexin: a combinatorial study with azithromycin and gentamicin. Sci Rep. 2016;6: 23347.

27. Hill L, Veli N, Coote PJ. Evaluation of Galleria mellonella larvae for measuring the efficacy and pharmacokinetics of antibiotic therapies against Pseudomonas aeruginosa infection. Int J Antimicrob Agents. 2014;43:254-61.

\section{Publisher's Note}

Springer Nature remains neutral with regard to jurisdictional claims in published maps and institutional affiliations.

Ready to submit your research? Choose BMC and benefit from:

- fast, convenient online submission

- thorough peer review by experienced researchers in your field

- rapid publication on acceptance

- support for research data, including large and complex data types

- gold Open Access which fosters wider collaboration and increased citations

- maximum visibility for your research: over $100 \mathrm{M}$ website views per year

At BMC, research is always in progress.

Learn more biomedcentral.com/submissions 